\title{
EDITORIAL
}

\section{A new Mental Health Act for England and Wales: grounds for compulsion}

\author{
Tony Zigmond
}

In the previous issue of APT (Zigmond, 2004) I described the process of law reform and the main issues raised in relation to the Draft Mental Health Bill. Here I focus on the grounds for making a person subject to compulsion and review the provisions in a number of jurisdictions.

\section{Definitions of mental disorder}

That a person suffers from mental disorder, or unsound mind as it is called in the European Convention on Human Rights and Fundamental Freedoms, is a necessary prerequisite for compulsion to be lawful within the terms of the Human Rights Act. Its definition is, therefore, crucial.

The Mental Health Act 1983 defines mental disorder as 'mental illness, arrested or incomplete development of mind, psychopathic disorder and any other disorder or disability of mind' It should be noted that the definition for three of the categories includes the further phrase 'abnormally aggressive or seriously irresponsible conduct'. Without this phrase, people with a learning disability or psychopathic disorder would be liable to detention any time they declined medical treatment for mental disorder.

The Draft Mental Health Bill (http://www. publications.doh.gov.uk/mentalhealth / draftbill2002/consdoc.htm) defines mental disorder as 'any disability or disorder of mind or brain which results in an impairment or disturbance of mental functioning'. This very broad definition, supported by the Expert Committee (Department of Health, 1999), was accepted by the Royal College of Psychiatrists, albeit only if combined with tight criteria for compulsion. It is very different from, for example, the definitions used in equivalent legislation in New Zealand or Australia (Box 1). It is self-evident that these definitions encapsulate psychotic disorders but probably not disorders of personality, an issue that has been central to the debate about the purpose of mental health law.

\section{Box 1 Definitions of mental disorder \\ Draft Mental Health Bill \\ 'Any disability or disorder of mind or brain which results in an impairment or disturb- ance of mental functioning.'}

Mental Health Act 1983 (my comments in brackets)

'Mental illness [undefined], arrested or incomplete development of mind [mental impairment, severe mental impairment], psychopathic disorder and any other disorder or disability of mind.'

New Zealand (Mental Health (Compulsory Assessment and Treatment) Act 1992):

'An abnormal state of mind shown by delusions or disorders of mood, perception, volition or cognition.'

Australia (New South Wales Mental Health Act 1990):

'Mental illness means a condition which seriously impairs, either temporarily or permanently, the mental functioning of a person and is characterised by the presence in the person of any one or more of the following symptoms:
a. delusions
b. hallucinations
c. serious disorder of thought form
d. a severe disturbance of mood.

Sustained or repeated irrational behaviour indicating the presence of one or more of the symptoms referred to in paragraphs a-d.'

Tony Zigmond is an adult psychiatrist with Leeds Mental Health Trust (Newsam Centre, Seacroft Hospital, York Road, Leeds LS14 6UH, UK. E-mail: Anthony.zigmond@leedsmh.nhs.uk). He is Vice-President of the Royal College of Psychiatrists and is the College lead on mental health law reform. 


\section{Criteria for compulsion and detention}

The criteria for compulsion and detention in the Draft Mental Health Bill are as follows:

'The first condition is that the patient is suffering from a mental disorder.

The second condition is that the mental disroder is of such a nature or degree as to warrant the provision of medical treatment to him.

The third condition is

a) in the case of a patient who is at substantial risk of causing serious harm to other persons, that it is necessary for the protection of those persons that medical treatment be provided to him and

b) in any other case, that

a. it is necessary for the health or safety of the patient or the protection of other persons that medical treatment be provided to him,

b. and that treatment cannot be provided unless he is made subject to the provisions of this Act.

The fourth condition is that appropriate medical treatment is available in the patient's case.'

One of the many concerns expressed about these criteria is that they authorise compulsion of patients even though the disorder might be relatively mild in severity. The White Paper that preceded this Bill had as its second criterion the requirement for 'specialist medical treatment', but this was removed. One of the criteria in the Mental Health Act 1983 is that the patient must be sufficiently ill to require admission to (Section 2) or treatment in (Section 3) hospital. This 'severity test' is absent both from the criteria in the Draft Bill and from those jurisdictions that permit compulsion in the community. This difficulty has been addressed in New Zealand and in Australia (New South Wales) by insertion of the word 'serious'. The New Zealand criteria state that compulsion is permitted if:

'there is a serious danger to your health and safety, or the health and safety of another person; or your ability to care for yourself is seriously reduced'.

An alternative approach to the use of compulsion is to make it one of the central criteria that the patient lacks capacity. In favour of this proposal is that it would bring the non-consensual treatment of people who are mentally ill in line with the treatment of those who are physically ill. Against it is the possibility that it might be too restrictive. In the UK, the Expert Committee thought that psychiatrists would be unable to stand back and permit a mentally ill person to come to harm just because the person retained capacity.

\section{Definitions of capacity}

A further difficulty might be how to define capacity and incapacity. Two rather different examples are given below. The Draft Mental Incapacity Bill states that:

'A person lacks capacity if, at the material time, he is unable to make a decision for himself in relation to the matter because of an impairment of or disturbance in the functioning of the mind or brain. This may be permanent or temporary.'

The common law definition of capacity is set out in Re C (Adult: Refusal of Medical Treatment) [1994]:

'A person retains capacity if able to understand, remember, believe, weigh in the balance necessary information and express a decision.'

It has been suggested that these definitions may rely too much on cognitive factors to be useful in relation to people who are mentally disordered. Despite these and other difficulties, it remains my view that, given proper provisions in an 'Incapacity' Act (or 'Capacity' Act as it is to become), a Mental Health Act would be unnecessary. These arguments are outside the scope of this editorial.

The new Scottish Mental Health (Care and Treatment) (Scotland) Act 2003 includes 'capacity' within the criteria, but uses a form of words that may be less restrictive:

'Because of the mental disorder the patient's ability to make decisions about the provision of such treatment is significantly impaired.'

This ensures that compulsion cannot be used in relation to patients who retain full decision-making capacity, yet allows considerable flexibility. The Act is due to come into force in April 2005, so we have yet to see how this will work in practice.

\section{Exclusion criteria}

The final part of any criteria for compulsion is the presence or absence of exclusion criteria. The exclusions in the current Mental Health Act are clear (although they may have been misunderstood). The absence of any exclusions from the Draft Mental Health Bill has been universally opposed. Examples from two other jurisdictions are shown in Box 2.

It can be seen that both the Scottish and the New Zealand criteria exclude compulsion on the sole grounds of sexual deviancy, substance misuse and, to differing degrees, antisocial behaviour (New South Wales has similar exclusion criteria, but expressed in a very verbose manner). These exclusions seem to many people and organisations to be essential in preserving the true spirit of mental 


\section{Box 2 Criteria for exclusion from compulsion}

Scotland:

'A person is not mentally disordered by reason only of any of the following: (a) sexual orientation, (b) sexual deviancy, (c) transexualism, (d) transvestism, (e) dependence on, or use of alcohol or drugs, (f) behaviour which causes, or is likely to cause harassment, alarm or distress to any other person, (g) acting as no prudent person would act (Mental Health (Care and Treatment) (Scotland) 2003)'

New Zealand:

'That person's political, religious, or cultural beliefs; or that person's sexual preferences; or that person's criminal or delinquent behaviour; or substance abuse; or intellectual disability.'

health legislation - which in my view is the very antithesis of the Government's intentions.

\section{Community treatment orders}

Breaking the link between compulsion and hospital is one of the central declared objectives of Government policy. The inclusion of community treatment orders changes the grounds for compulsion both in theory, by removing the need for a patient to be ill enough to warrant admission to hospital, and in practice, by removing the need to find a bed.

Opinion as to their appropriateness is, as ever, split. Are they a 'less restrictive alternative' or 'compulsion for evermore'? User groups are absolutely opposed. Colleagues have expressed a range of views, from outright opposition, through believing that they should be available only after an in-patient assessment, to being in favour of their use at any time. They are part of the legislation in New Zealand and Australia (and mentioned frequently as being successful in these jurisdictions by the Department of Health, hence my focusing on the grounds for compulsion in those countries).

In New Zealand (and in New South Wales) these orders are available at any time but, owing to the narrow definition of mental disorder and strict criteria, are rarely applied prior to admission. A rather different model is that in use in the Canadian province of Saskatchewan (Box 3). These criteria require not only that the patient has a relapsing illness but also (penultimate bullet point) that the patient lacks full decision-making capacity.
Box 3 Criteria for the use of a community treatment order in Saskatchewan, Canada (after the New South Wales Mental Health Act 1990)

- The person must have a mental disorder for which he or she is in need of treatment or care that can be provided in the community.

- In the previous 2 years the person must have spent at least 60 days as an involuntary inpatient in a psychiatric facility, or

have been an involuntary in-patient in a psychiatric facility on three or more separate occasions, or

have previously been the subject of a community treatment order.

- There must be a likelihood that, if the person were not to receive treatment while residing in the community, he or she would cause harm to self or others or suffer substantial mental or physical deterioration as a result of the mental disorder.

- The services the person requires in order to reside in the community must be available in the community.

- The person must be unable to understand and to make an informed decision regarding his or her need for treatment, care or supervision as a result of the mental disorder.

- The person must be capable of complying with the requirement for treatment and supervision contained in the community treatment order.

Currently the College's approach is to support the use of community treatment orders, but only following compulsory in-patient care.

\section{Clinical supervisors}

Finally, although not part of grounds for detention, I should mention the role of the clinical supervisor. Some colleagues believe that psychiatrists are the only professionals with sufficient breadth of training to undertake this role. Others take the view that, with modern multidisciplinary teams, the natural 'leader' for a particular patient may come from one of a number of different disciplines. Both views are easily supportable. There is, however, an aspect of the role that has not been addressed.

One of the responsibilities placed upon a 'responsible medical officer' (RMO) is the duty, in relation to the detained patient, to keep under constant review whether or not the criteria for detention 
continue to be met. If the patient no longer meets the criteria for detention the RMO should discharge the patient from detention under section. It is clear that only doctors (registered medical practitioners) are deemed qualified to recommend detention or compulsion (this remains true under the provisions of the Draft Bill). There remains a question, therefore, as to whether or not a non-medical clinical supervisor could fulfil this obligation.

\section{Conclusions}

In these two editorials I hope that I have given some idea of the process of law reform and the difficulties, and range of options, in determining College policy (let alone a policy agreed with the 60 organisations that make up the Mental Health Alliance).
Your views will continue to be welcome until the process is complete. As I write, we know only that the Joint Select Committee will sit before the Queen's Speech in November 2004. The revised Draft Bill will clearly need to be published some time prior to this.

Will all this effort achieve anything? It already has. Never before have two draft bills on the same subject been presented to Parliament. We have made history.

\section{References}

Department of Health (1999) Review of the Mental Health Act, Report of the Expert Committee. London: Department of Health.

Zigmond, A. (2004) A new Mental Health Act for England and Wales. Advances in Psychiatric Treatment, 10, 161-163.

Re C (Adult: Refusal of Medical Treatment) [1994] 1 All ER 819.

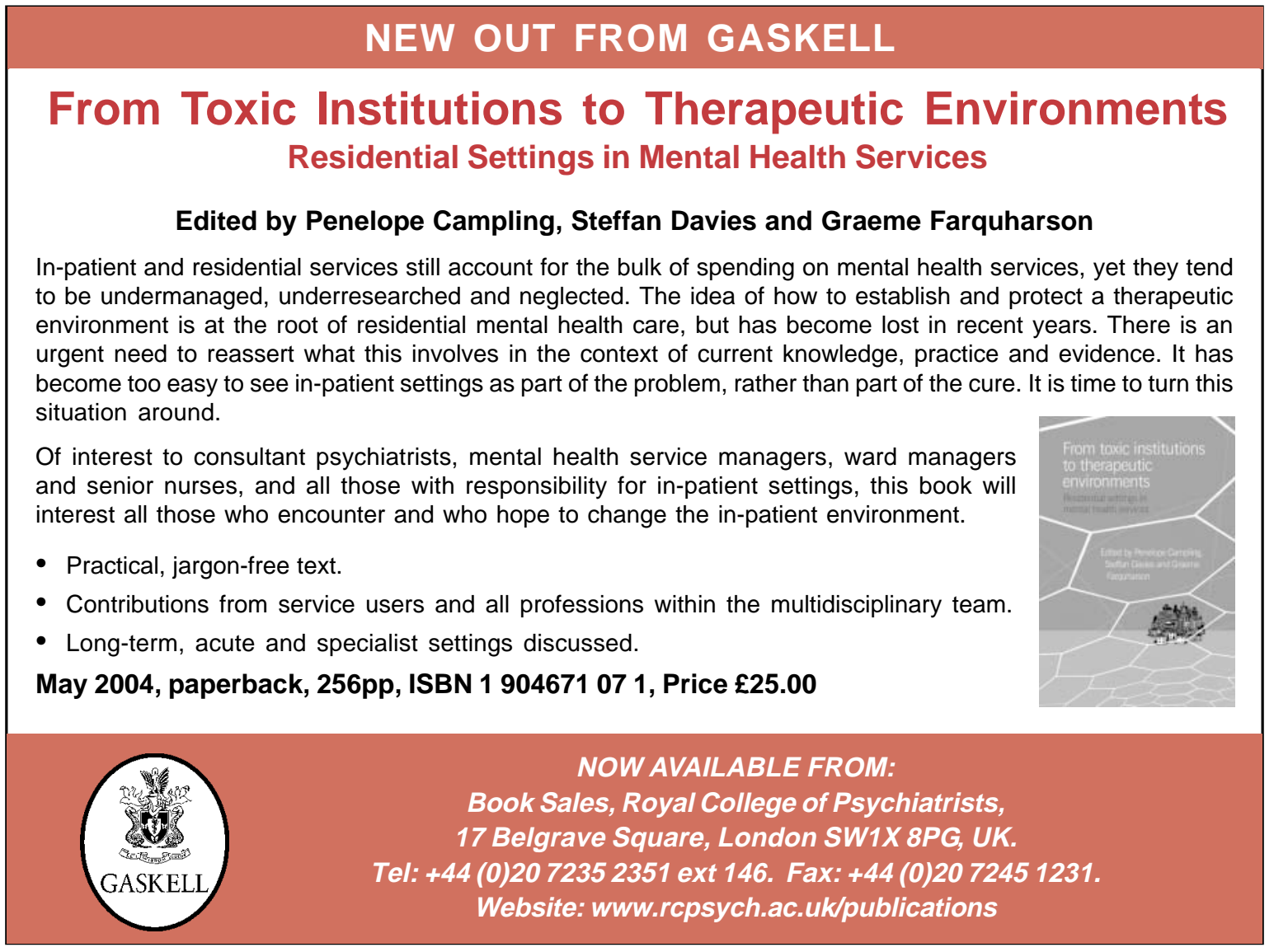

